\title{
ERRATUM: A childhood case of spinal tuberculosis misdiagnosed as muscular dystrophy
}

Korean J Pediatr 2010;53(5):657-660

Doo Il Song, M.D.', Su Ye Sohn, M.D.', Yun Kyung Kim, M.D., So Hee Eun, M.D.', Young Jun Rhie, M.D.', Gi Young Jang, M.D. ., Chan Wook Woo, M.D. ', Byung Min Choi, M.D. ', Jung Hwa Lee, M.D. ${ }^{1}$ and Bo Kyung Je, M.D. ${ }^{2}$

Department of Pediatrics', Department of Radiology ${ }^{2}$, College of Medicine, Korea University, Seoul, Korea

In the article by Song Doo Il et al. that starts on page 657 of Volume 53, Number 5 of Korean J Pediatr (May 2010), the figures were misplaced due to an editing error. The editors regrets this error and any confusion it has caused. The correct Figure 2 and Figure 3 appear below.

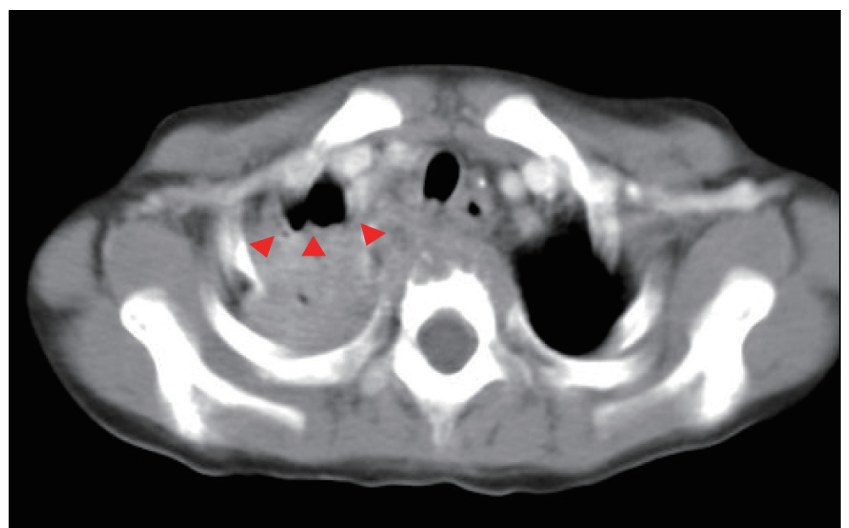

Fig. 2.

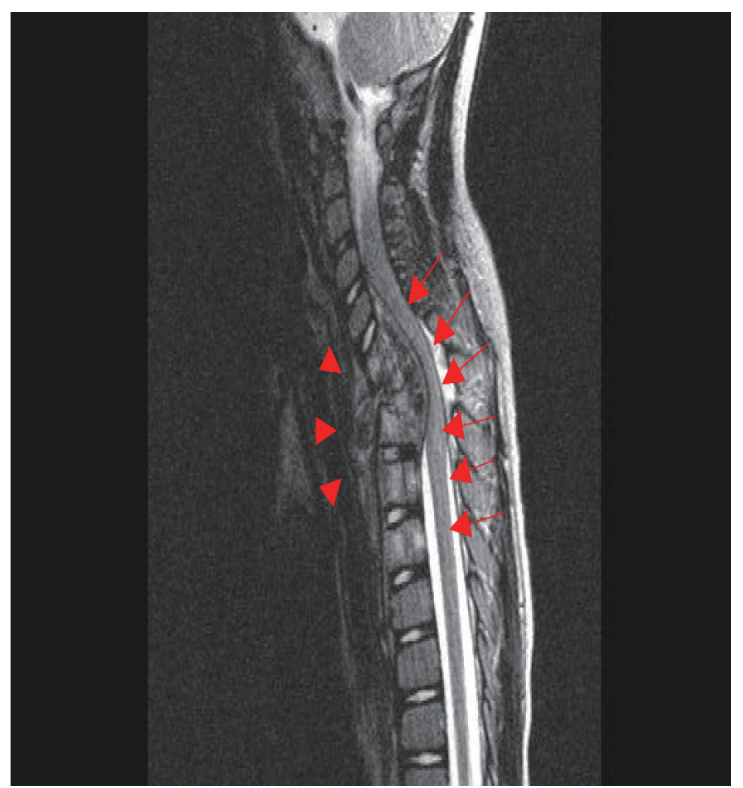

Fig. 3. 